\title{
Analysis of the Effect of Intestinal Resection on Rat Ileal Bile Acid Transporter Expression and on Bile Acid and Cholesterol Homeostasis
}

\author{
NAMIR AL-ANSARI, GUORONG XU, KATIE KOLLMAN-BAUERLY, CHRIS COPPOLA, \\ SARAH SHEFER, PETER UJHAZY, DANIEL ORTIZ, LIN MA, STEVEN YANG, RICHARD TSAI, \\ GERALD SALEN, JON VANDERHOOF, AND BENJAMIN L. SHNEIDER \\ Mount Sinai School of Medicine, New York, New York, U.S.A. [N.A.-A., L.M., B.L.S.]; Veterans Affairs \\ Medical Center, East Orange, New Jersey, U.S.A. [G.X., G.S.]; University of Nebraska/Creighton \\ University, Omaha, Nebraska, U.S.A. [K.K.-B., J.V.]; Yale University School of Medicine, New Haven, \\ Connecticut, U.S.A. [C.C.]; University of Medicine and Dentistry of New Jersey, Newark, New Jersey, \\ U.S.A. [G.X., S.S., S.Y., R.T., G.S.]; and Tufts University School of Medicine, Boston, Massachusetts, \\ U.S.A. [P.U., D.O.]
}

\begin{abstract}
Ileal reclamation of bile salts is mediated in large part by an apical sodium-dependent bile acid transporter (ASBT) located in the terminal ileum. The following studies were performed to elucidate the adaptive response of ASBT to intestinal resection. Two separate series of intestinal resections were performed: 1) limited (25\%) ileal and 2) massive (70\%) intestinal resection. The boundaries of the resections were varied to examine differences in compensation when variable amounts of endogenous transporter activity were resected. Previously demonstrated supraphysiologic expression of ASBT, which was seen after proximal ileal resection, led to a contraction in the bile acid pool size and a paradoxical reduction in bile acid (cholesterol $7 \alpha-$ hydroxylase and sterol 27-hydroxylase) and cholesterol (hydroxymethylglutaryl coenzyme A reductase) biosynthetic enzyme activities. Massive intestinal resection resulted in ileal
\end{abstract}

\section{ABSTRACT}

hypertrophy and an apparently maladaptive specific downregulation in ASBT protein expression. In this model bile acid pool size correlated with the amount of residual ASBTexpressing terminal ileum. Cholesterol and bile acid biosynthetic enzyme activities were inversely related to bile acid pool size. Adaptive changes in ASBT expression and alterations in bile acid and cholesterol homeostasis are dependent on the type and location of intestinal resection. (Pediatr Res 52: 286-291, 2002)
Abbreviations
ASBT, apical sodium-dependent bile acid transporter
ILBP, ileal lipid-binding protein
FIC1, familial intrahepatic cholestasis-1
HMG, hydroxymethylglutaryl

Intestinal bile acid absorption in the rat primarily takes place in the terminal ileum. At least two specific proteins appear to mediate this process; one of these is ASBT, which facilitates uptake of bile acid from the ileal lumen (1). The other protein is ILBP, which binds bile acids within the enterocyte. It has been shown from previous studies on rats that bile acid transporter gene expression occurs predominantly in the terminal 30 $\mathrm{cm}$ of small intestine (2). Therefore, distal but not proximal native ileum expresses ASBT. After limited $(25 \%$ of total small bowel length) resection, transport and expression were found only in the remaining portions of terminal ileum.

Received June 6, 2001; accepted February 8, 2002.

Correspondence and reprint requests: Benjamin L. Shneider M.D., Mount Sinai Medical Center, Box 1656, One Gustave L. Levy Place, New York, NY 10029, U.S.A.; e-mail: Benjamin.Shneider@mssm.edu

Supported by grants from the National Institutes of Health DK 02076 and DK 54165.

DOI: 10.1023/01.PDR.0000020100.00415.F1
Certain conditions affecting the gastrointestinal tract may require extensive intestinal resection as a treatment, which may eventually result in short gut. Examples of these conditions include necrotizing enterocolitis, Crohn's disease, midgut volvulus, mesenteric vascular disease, intestinal atresia, and irradiation or cancer (3). Within 24 to $48 \mathrm{~h}$ after a bowel resection, the remaining small intestine begins to undergo an adaptive process characterized by epithelial hyperplasia. As this process progresses, villi lengthen and intestinal absorptive surface area increases as much as 4-fold. Enhancement of digestive and absorptive function may lag behind the increase in mucosal surface area. As the jejunum normally has more absorptive capacity, the ability of the ileum to adapt is greater than that of the jejunum (4).

Many processes are deranged in short gut syndrome, one of which is the interruption in the normal enterohepatic circulation of bile acids caused by loss of bile acid transport capacity. 
The adaptive response of the gastrointestinal tract to massive intestinal resection, resulting in surgical short gut and in loss of bile acid transport capacity, is not well characterized.

Limited ileal resection (proximal or distal) leads to hyperplasia, which nonspecifically increases ASBT and other brush border proteins irrespective of whether the transporter itself is resected (2). As a result, proximal ileal resection, in which ASBT is not resected, leads to a supraphysiologic expression of the distal ileal sodium-dependent bile acid transporter. However, it is not known what adaptive changes occur in cholesterol and bile acid metabolism in response to supraphysiologic expression of ASBT. Therefore, the effect of proximal versus distal ileal resection on bile acid pool size and on bile acid biosynthetic enzyme activities was determined. Surprisingly, our studies found that bile acid pool size was reduced after proximal ileal resection and there was a paradoxical down-regulation in bile acid and cholesterol biosynthetic enzyme activities.

To extrapolate these findings, a series of short gut models was assessed. Short gut physiology was induced by $70 \%$ small intestinal resection. By altering the sites of the proximal and distal margins of resection, various lengths of ASBTexpressing tissue were left in place. These models then had the potential to augment the supraphysiologic expression of ASBT seen in proximal ileal resection by inducing an additional increment in ASBT expression caused by the ileal hypertrophy associated with the adaptive response to the short gut. The expression of a variety of ileal proteins, including ASBT, ILBP, I100, and FIC1, was determined. I100 is an ileal brush border membrane protein with dipeptidyl peptidase IV activity whose exact physiologic role is not known (5). FIC1 is an intestinal protein that is defective in progressive familial intrahepatic cholestasis type 1 [Byler's disease (6)]. This study also included the evaluation of the response in cholesterol and bile acid metabolism in these surgical short gut models as elicited by synthetic enzyme activity and pool size.

\section{METHODS}

Animals. Male Sprague-Dawley rats (mean weight, $250 \pm$ $50 \mathrm{~g}$ ) were obtained from Charles River Laboratory Inc. (Wilmington, MA, U.S.A.). Animals were cared for by approved studies according to the guidelines of the animal review committees at Yale University School of Medicine, New Haven, CT, U.S.A.; Mount Sinai School of Medicine, New York, NY, U.S.A.; and University of Nebraska Medical Center, Omaha, NE, U.S.A.. Rats were housed individually in hanging wire cages and acclimated for $3 \mathrm{~d}$ to laboratory conditions. Rats were fed regular rat chow, but they were not fed for $24 \mathrm{~h}$ after surgery, but received $5 \%$ glucose water containing $0.0225 \%$ tetracycline ad libitum.

Surgical procedures. Rats were anesthetized with an intramuscular injection of xylazine (Burns Veterinary Supply, Inc., Rockville Center, NY, U.S.A.) and ketamine (Fort Dodge Laboratories, Fort Dodge, IA, U.S.A.), $9.75 \mathrm{mg} / \mathrm{kg}$ and 60 $\mathrm{mg} / \mathrm{kg}$, respectively. The abdomen was shaved and scrubbed with Betadine. A midline incision was made, and the small intestine was isolated.
Proximal versus distal resection. To assess proximal versus distal resection, rats were divided into two groups: group 1 had proximal ileal resection, and group 2 had distal ileal resection (Fig. 1A). Ten rats underwent enterotomies at 45, 70, and 95 $\mathrm{cm}$ along the $100 \mathrm{~cm}$ of the small intestine. In group 1 (proximal resection), the segment from 45 to $70 \mathrm{~cm}$ was resected and the segment at $95 \mathrm{~cm}$ was reanastomosed. In group 2 (distal resection), the segment at $45 \mathrm{~cm}$ was reanastomosed and the segment between 70 and $95 \mathrm{~cm}$ was resected.

Adaptation to massive intestinal resection. Thirty-two rats were studied and a series of surgical short gut models were created. Rats were divided into four groups, three receiving $70 \%$ resection, and the other receiving a sham operation. Resected rats were further divided into three surgical groups ( $n$ $=5$ in each), leaving $5 \mathrm{~cm}, 15 \mathrm{~cm}$, or $25 \mathrm{~cm}$ of the terminal ileum (Fig. 1B). For a 70\% resection, the bowel was divided and removed between $25 \mathrm{~cm}$ distal to the ligament of Treitz and $5 \mathrm{~cm}$ proximal to the ileocecal valve $(5-\mathrm{cm}$ residual terminal ileum), $15 \mathrm{~cm}$ distal to the ligament of Treitz and 15 $\mathrm{cm}$ proximal to the ileocecal valve $(15-\mathrm{cm}$ residual terminal ileum), or $5 \mathrm{~cm}$ distal to the ligament of Treitz and $25 \mathrm{~cm}$ proximal to the ileocecal valve $(25-\mathrm{cm}$ residual terminal ileum). Intervening mesenteric vessels were ligated with 5-0 silk. The remaining jejunum was reanastomosed to the distal ileum using interrupted sutures of 6-0 silk. Control animals were

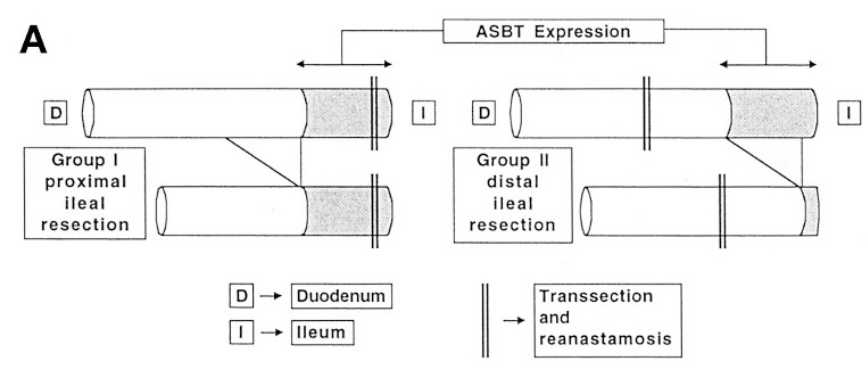

B
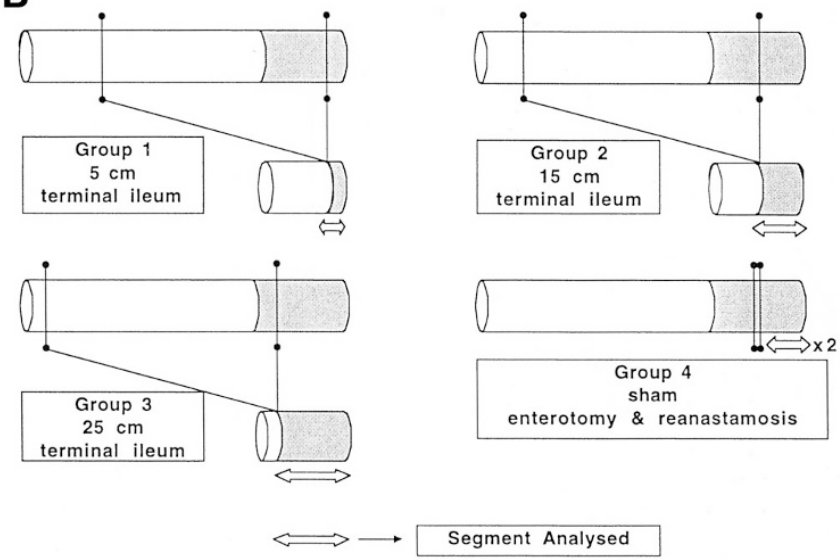

Figure 1. Diagrams of intestinal resections. A, proximal vs distal resection model. Proximal ileal resection consisted of removal of the $25 \mathrm{~cm}$ of ileum just proximal to the site of endogenous ASBT-expressing tissue. In contrast distal ileal resection consisted of removal of the majority of the endogenously expressing ASBT tissue. $B$, massive intestinal resection model. Seventy percent of the small intestine was removed in three groups of animals. The proximal and distal boundaries of the resection were varied so that 5,15 , or 25 $\mathrm{cm}$ of terminal ileum remained intact. Sham surgery involved enterotomy and reanastomosis $15 \mathrm{~cm}$ from the ileocecal valve. 
subjected to a sham operation consisting of a division of the bowel at $15 \mathrm{~cm}$ from the ileocecal valve and subsequent reanastomosis.

All animals were killed 3 wk postoperatively. Twenty animals were used for preparation of ileal proteins and for the analysis of hepatic enzyme activities. Ileal mucosa from the appropriate intestinal segment was obtained. In the sham operated group the terminal $15 \mathrm{~cm}$ of ileum was collected and results were doubled for the assessment of total activity. Liver tissue was also obtained from each animal. All tissues were snap-frozen in liquid nitrogen and stored at $-80^{\circ} \mathrm{C}$. Twelve animals were used for bile acid pool size analysis.

Preparation of crude brush border membrane vesicles. Crude brush border membrane vesicles were prepared as previously described (7). The remaining intestine from the anastomosis to the ileocecal valve was removed and stripped of its mesentery. The bowel was flushed with cold isotonic saline, and the $1 \mathrm{~cm}$ adjacent to the anastomosis was removed as this tissue was subjected to hyperplastic artifact caused by vascular neoplasia. The remaining ileum was measured for length and weight, opened on the antimesenteric border, and subsequently scraped with a glass slide on a cold glass surface to remove mucosa from underlying tissue. Ileal mucosa was homogenized

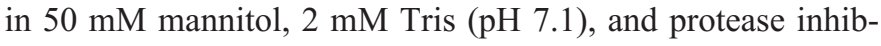
itors (leupeptin $25 \mu \mathrm{g} / \mathrm{mL}$, aprotinin $5 \mu \mathrm{g} / \mathrm{mL}$, phenylmethylsulfonyl fluoride $40 \mu \mathrm{g} / \mathrm{mL}$, benzamide $50 \mu \mathrm{g} / \mathrm{mL}$, and pepstatin $0.5 \mu \mathrm{g} / \mathrm{mL}$ ). An aliquot of the homogenate was set aside for Western blotting of ILBP. Homogenates were incubated with gentle stirring for $15 \mathrm{~min}$ at $4{ }^{\circ} \mathrm{C}$ with $10 \mathrm{mM} \mathrm{CaCl}_{2}$. Cellular debris and nuclei were removed with a 10 -min $2,978 \times g$ centrifuge, and then crude apical membranes were sedimented at $29,890 \times g$ for $20 \mathrm{~min}$. The resulting pellet was then suspended in $300 \mathrm{mM}$ mannitol, $10 \mathrm{mM}$ HEPES-Tris (pH 7.5), and protease inhibitors. Aliquots for Western blotting were stored at $-80^{\circ} \mathrm{C}$. Protein concentrations were determined using the Bradford method (Bio-Rad, Richmond, CA, U.S.A.) with $\mathrm{BSA}$ as the standard.

Western blot analysis. Western blotting was performed for detection of ASBT, ILBP, I100, and FIC1 in the mucosa of residual ileum. Both specific expression (units per milligram of protein) and total expression (specific expression times total protein for residual ileum) were measured. Antibody used for detection of ASBT was a previously characterized carboxylterminal antipeptide antibody; for ILBP, an anti-mouse polyclonal antibody; for I100, an anti-rat polyclonal antibody; and for FIC1, an anti-rat polyclonal antibody. Immunodetection was performed in the linear portion of the response curve for the given antibody and antigen $(15 \mu \mathrm{g}$ of protein for ASBT, 10 $\mu \mathrm{g}$ of protein for ILBP, $10 \mu \mathrm{g}$ of protein for I100, $8 \mu \mathrm{g}$ of protein for FIC1). Primary antibody was detected with 3 $\mu \mathrm{Ci} / 20 \mathrm{~mL}$ of ${ }^{125}$ I-labeled protein A secondary antibody. The signals of ASBT (48 kD) (8), ILBP (14 kD) (9), I100 (100 kD) (5), and FIC1 (145 kD) (10) were quantified using a phosphorimager (Amersham Pharmacia Biotech, Sunnyvale, CA, U.S.A.).

Analysis of bile acid synthetic enzyme activity. Activity of cholesterol and bile acid synthetic enzymes (HMG-CoA reductase, cholesterol $7 \alpha$-hydroxylase and sterol 27-hydroxylase) was assessed as previously described (11). Hepatic microsomes and mitochondria were prepared by differential ultracentrifugation (12), and protein was determined according to Lowry et al. (13). Hepatic microsomes were used to determine the activities of HMG-CoA reductase and cholesterol $7 \alpha$ hydroxylase. The assay for HMG-CoA reductase activity was the same as described previously (14). Cholesterol $7 \alpha$ hydroxylase activity was measured in hepatic microsomes after removal of endogenous lipid by acetone and reconstituting the microsomal protein with cholesterol and optimal amounts of cofactors by the isotope incorporation method of Shefer et al. (12). Mitochondrial sterol 27-hydroxylase activity was assayed by an isotope incorporation method as described previously by Shefer et al. (15).

Analysis of bile acid pool size. Bile acid pool size was measured as previously described (11). The measurement of bile acid pool size required construction of a bile fistula. The same animals cannot be used for this purpose as well as bile acid transporter and synthetic enzyme activity measurement, as this procedure may consequently affect the ileal bile acid transporter expression and cholesterol and bile acid synthetic enzyme activity measurement. Therefore, a separate series of rats was used which received surgical procedures identical to the initial groups in both models (proximal versus distal resection model and adaptation to massive intestinal resection model). Three weeks later, these rats had surgical procedures to establish bile fistula for the recovery of bile acids similar to that for rabbits as described previously (2). Bile was collected continuously for $2 \mathrm{~d}$, as the bile acid pool is completely depleted in $24 \mathrm{~h}$ in rats. The bile acid pool size was measured by the method of Mok et al. (16).

Analysis of results. Results are expressed as mean \pm SD. Results were compared by either $t$ test or one-way ANOVA using the Tukey-Kramer multiple comparisons test (for multiple means). Differences were considered significant at a probability level of $<5 \%$. Results were converted into percent values to compare among different groups, considering the sham group values as $100 \%$.

\section{RESULTS}

Proximal versus distal resection model. Previous studies have shown that specific expression of ASBT and ILBP were similar after either proximal or distal ileal resections (2). Compensatory hyperplasia was seen in both models. Because the ASBT-expressing terminal ileum was intact in the proximal resection model, supraphysiologic expression of ASBT was observed. Analysis of ASBT and ILBP expression was not repeated for this model in these studies. The supraphysiologic expression of ASBT was accompanied by a contraction of the bile acid pool size (proximal resection, $19.1 \pm 6.8 \mathrm{mg}$ versus distal resection, $34.7 \pm 10.5 \mathrm{mg} ; p<0.05$; Fig. 2). In the setting of a diminished bile acid pool size, cholesterol and bile acid synthetic enzyme activities were reduced (proximal versus distal resection; HMG-CoA reductase, $55.6 \pm 5.2$ versus 88.8 $\pm 3.3 \mathrm{pmol} \cdot \mathrm{mg}^{-1} \cdot \mathrm{min}^{-1}$; cholesterol $7 \alpha$-hydroxylase, $30.0 \pm$ 1.2 versus $49.7 \pm 4.1 \mathrm{pmol} \cdot \mathrm{mg}^{-1} \cdot \mathrm{min}^{-1}$; and sterol 27 - 


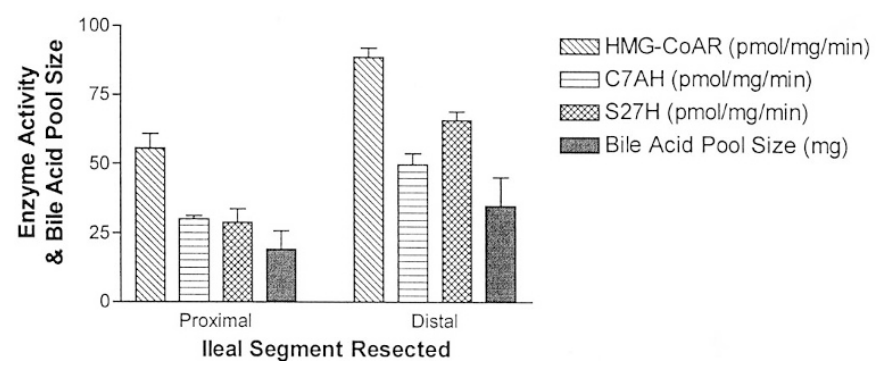

Figure 2. Cholesterol and bile acid biosynthetic enzyme activities and bile acid pool size (proximal $v s$ distal model). Enzyme activities were measured in liver $3 \mathrm{wk}$ after intestinal resection. The bile acid pool size is reduced in proximal $v s$ distal ileal resection $(p<0.05)$. Paradoxically, bile acid [ 7a-hydroxylase $(\mathrm{C} 7 \mathrm{AH})$ and sterol 27 hydroxylase $(\mathrm{S} 27 \mathrm{H})]$ and cholesterol (HMG-CoA reductase) biosynthetic enzyme activities are also reduced in proximal $v s$ distal resection $(p<0.05)$.

hydroxylase, $28.7 \pm 5.0$ versus $65.8 \pm 3.2 \mathrm{pmol} \cdot \mathrm{mg}^{-1} \cdot \mathrm{min}^{-1}$; all $p<0.05$ ).

Massive intestinal resection model. All animals tolerated massive intestinal resection well, and weight gain was similar in all four groups (data not shown). Unlike the limited resection above, specific expression of ASBT was reduced in the residual ileum of rats in the groups with massive intestinal resection compared with the sham group. Statistically significant reduction was observed in the $25-\mathrm{cm}$ group only (ASBT phosphorimager units/mg membrane protein: $5-\mathrm{cm}, 3440 \pm$ 1418 ; $15-\mathrm{cm}, 3902 \pm 2115 ; 25-\mathrm{cm}, 2330 \pm 1765$; sham, 6347 $\pm 1861 ; p<0.01$ for $25-\mathrm{cm}$ relative to sham; Figs. $3 A$ and 4$)$. Quantitation of the monomer form of ASBT or of the sum of all of the oligomers of ASBT yielded similar results (data not shown). In contrast, there was no significant difference in specific expression of ILBP, I100, and FIC1 among different groups (Fig. $3 A$ ). Total protein expression was dependent on the length of residual terminal ileum and the degree of hypertrophy and hyperplasia (total brush border membrane protein in mg: 5 -cm, $0.54 \pm 0.17 ; 15-\mathrm{cm}, 1.05 \pm 0.19 ; 25-\mathrm{cm}, 3.2 \pm$ 0.61 ; sham, $0.88 \pm 0.15 ; p<0.001$ sham $v s 25-\mathrm{cm} ; p<0.001$ $15-\mathrm{cm}$ vs $25-\mathrm{cm} ; p<0.0015-\mathrm{cm}$ vs $25-\mathrm{cm})$. Total ASBT expression increased proportional to the length of residual terminal ileum, although it never reached the level of expression observed in the sham-operated group (ASBT phosphorimager units: 5 -cm, $1879 \pm 1363 ; 15-\mathrm{cm}, 3946 \pm 1871 ; 25-\mathrm{cm}$, $6682 \pm 4230$; sham, $11211 \pm 1969 ; p<0.05$ for 5 -cm $v s$ $25-\mathrm{cm} ; p<0.0115-\mathrm{cm} v s$ sham; $p<0.0015$-cm $v s$ sham; Fig. $3 B)$. Total expression of ILBP, I100, and FIC1 was also proportional to the length of residual terminal ileum. Total expression was low in animals with $5 \mathrm{~cm}$ of residual ileum (\% of sham: ILBP, $27 \%$; I100, 30\%; FIC1, 32\%). Inasmuch as the specific expression of these gene products was not downregulated, total expression was supraphysiologic in those animals with $25 \mathrm{~cm}$ of residual terminal ileum (\% of sham: ILBP, 165\%; I100, 208\%; FIC1, 212\%).

Bile acid pool size was proportional to the length of residual ileum $(5-\mathrm{cm}, 17.4 \pm 4.3 \mathrm{mg} ; 15-\mathrm{cm}, 27.7 \pm 10.1 \mathrm{mg} ; 25-\mathrm{cm}$, $36.5 \pm 10.2 \mathrm{mg}$; sham, $37.1 \pm 9.7 \mathrm{mg}$; Fig. 5). Cholesterol and bile acid biosynthetic enzyme activities were inversely proportional to the length of residual ileum. Compensation in HMG-
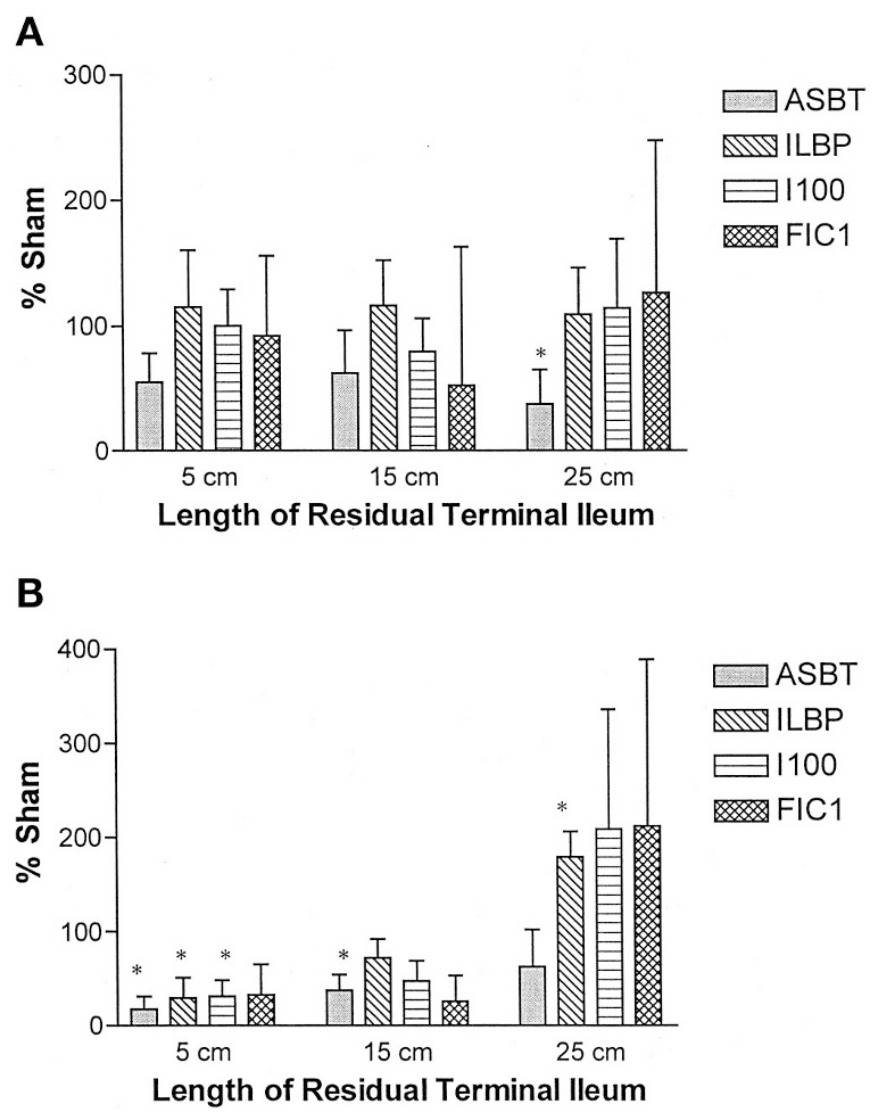

Figure 3. Analysis of ileal protein expression after $70 \%$ intestinal resection. $A$, specific expression of ASBT, ILBP, I100, and FIC1 in the residual terminal ileum in different groups. Massive $(70 \%)$ intestinal resection was performed with 5,15 , or $25 \mathrm{~cm}$ of residual terminal ileum left intact. Specific expression of ASBT protein, as measured by quantitative Western blotting, is reduced in animals that underwent massive intestinal resection, whereas ILBP, I100, and FIC1 are unchanged $\left({ }^{*} p<0.05\right.$ for ASBT in 25-cm group $v s$ sham). $B$, total expression of ASBT, ILBP, I100, and FIC1 in the residual ileum of different groups. Total expression was calculated by multiplying the specific expression for a given animal by the total amount of ileal protein (brush border membrane proteins for ASBT, I100, and FIC1; homogenate protein for ILBP) for that animal. Adaptation with $5 \mathrm{~cm}$ of residual ileum does not reach sham levels, whereas compensatory hypertrophy of the residual ileum leads to supraphysiologic expression of ILBP, I100, and FIC1 when $25 \mathrm{~cm}$ of ileum is left in place. Total ASBT expression does not reach the level of sham-operated animals, because of specific down-regulation of ASBT expression. ${ }^{*} p<0.05$, significantly different from sham.

CoA reductase activity was most dramatic $(5-\mathrm{cm}, 134.5 \pm 60.0$ $\mathrm{pmol} \cdot \mathrm{mg}^{-1} \cdot \mathrm{min}^{-1} ; 15-\mathrm{cm}, 79.7 \pm 26.0 \mathrm{pmol} \cdot \mathrm{mg}^{-1} \cdot \mathrm{min}^{-1}$; $25-\mathrm{cm}, 34.3 \pm 10.0 \mathrm{pmol} \cdot \mathrm{mg}^{-1} \cdot \mathrm{min}^{-1}$ ).

\section{DISCUSSION}

Bile acid deficiency is important in the pathogenesis of fat malabsorption in patients with ileal resection $(17,18)$. In humans, resection of the terminal ileum causes bile acid malabsorption (19). If the resection is small, the effect on bile acid metabolism is minimal. Increased biosynthesis occurs to compensate for the increased loss. With larger resections, bile acid synthesis increases even further, up to 20 times the usual rate. When the length of the ileum resected is greater than $100 \mathrm{~cm}$, bile acid secretion decreases because the increased bile acid 

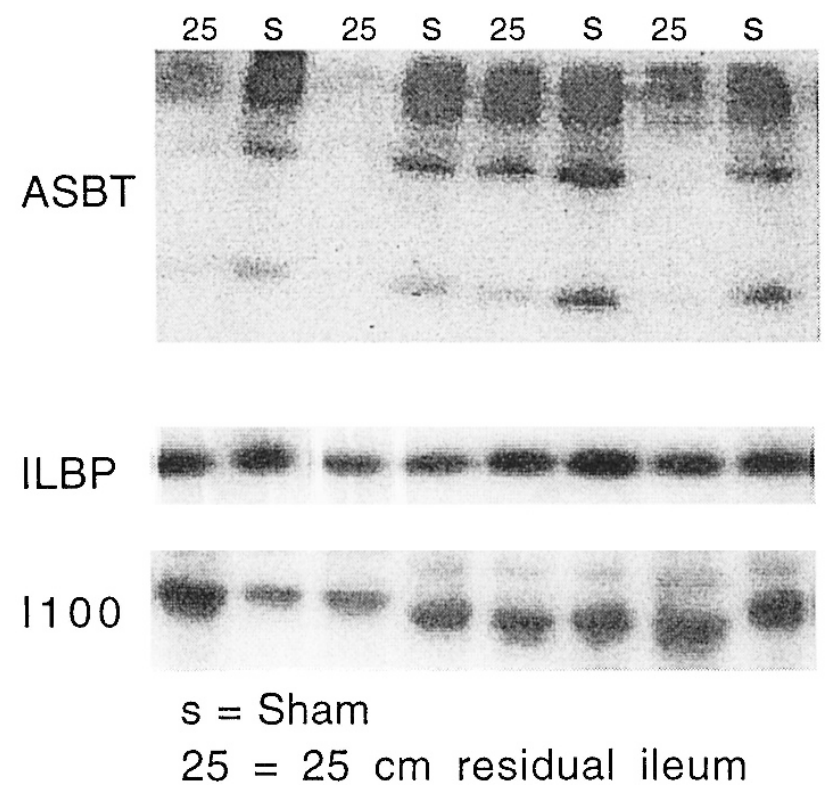

Figure 4. Western blot analysis of ASBT, ILBP, and I100 expression in 25-cm residual ileum group and sham group after massive intestinal resection. A representative Western blot is shown. Monomer, dimer, and oligomers of the ASBT protein are seen. Compared with sham-operated animals $(S)$, ASBT protein expression is reduced in animals that underwent $70 \%$ intestinal resection that spared $25 \mathrm{~cm}$ of residual terminal ileum (25). Specific expression of ILBP and I100 protein was unchanged.

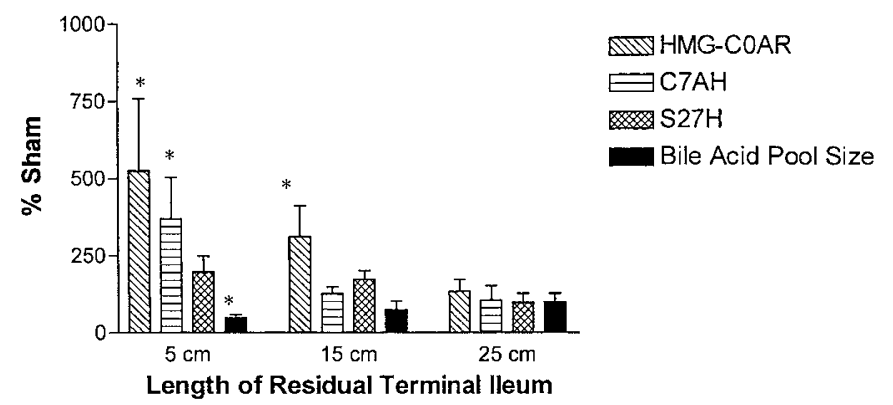

Figure 5. Cholesterol and bile acid biosynthetic enzyme activities and bile acid pool size after massive intestinal resection. Bile acid pool size is proportional to the length of residual ileum. There is an inverse relationship between bile acid pool size and bile acid and cholesterol biosynthetic enzyme activity. $* p<0.05$, significantly different from sham. See Figure 2 for abbreviations.

synthesis (3000-6000 $\mathrm{mg} / \mathrm{d})$ is still well below the normal bile acid secretion rate. Treatment with cholylsarcosine, a synthetic conjugated bile acid, improved fat absorption in short bowel syndrome patients (20). Therefore, conjugated bile acid replacement therapy should be considered as a therapeutic adjunct for treatment of patients with short bowel syndrome who have some residual small intestine (21). The clinical implications of bile acid malabsorption in short bowel syndrome necessitate an increased understanding of the adaptation of ileal bile acid transport to intestinal resection.

The adaptive response to small intestinal resection involves complex morphologic, cellular, and molecular responses (22). The morphologic alterations are in the form of hypertrophy and hyperplasia of the residual small intestine with increase in crypt depth and villus height. These changes result in an increase in the small intestinal surface area, which enhances overall intestinal absorption in a nonspecific fashion. The cellular and molecular responses are potentially more complex and have the capacity to induce specific physiologic changes in transport and digestive capacity. Only a limited number of molecular investigations of the short gut adaptation of specific transporters and digestive enzymes have been performed (2, 23-27). In most circumstances intestinal resection leads to a compensatory up-regulation in transporter or digestive enzyme expression (23-26).

The initial studies performed in these investigations were directed at understanding the physiologic consequences of supraphysiologic expression of ASBT that was associated with proximal ileal resection. Surprisingly, the total bile acid pool was diminished after proximal ileal resection, where there was supraphysiologic expression of ASBT. Paradoxically in the face of a reduced bile acid pool, bile acid and cholesterol biosynthetic enzyme activities were reduced. These findings are difficult to reconcile with current concepts of feedback regulation of bile acids on their synthetic enzymes (28). One potential explanation is that supraphysiologic expression of ASBT leads to a contracted bile acid pool that cycles more frequently. As such hepatocytes are exposed to a greater flux of bile acids, despite a reduction in overall pool size. Further investigation of the regulatory molecules, farnesoid $\mathrm{X}$ receptor, liver $\mathrm{X}$ receptor, and short heterodimer partner, will be instructive in understanding this system (28-31).

To explore these findings an additional series of intestinal resections was performed. In our previous studies limited intestinal resection was not associated with a specific change in bile acid transporter expression, although hyperplasia led to supraphysiologic transporter expression when the distal ileum was left intact (2). Interestingly, in these studies 70\% resection was associated with a very different specific response of ASBT compared with that seen when $85 \%$ resection was performed (2). This suggests that there may be threshold levels of residual intestine for different types of adaptive response. Massive intestinal resection was performed in these studies to induce hypertrophy and potentially accentuate the supraphysiologic expression of ASBT. Supraphysiologic expression of ILBP, I100, and FIC1 was observed in rats who had the terminal ileum spared. Unexpectedly and in contrast to previous studies, steady-state ASBT protein expression was specifically downregulated after massive intestinal resection. This prevented supraphysiologic ASBT expression and in fact led to a relative deficiency in ASBT and a commensurate bile acid wasting. A similar down-regulation after massive intestinal resection has been observed for dipeptidyl peptidase IV mRNA (27). Downregulation of ASBT after small bowel resection appears to be maladaptive, and further investigation of this phenomenon may lead to important new approaches for the treatment of short gut.

A novel and additional aspect of these studies was integration of the effects of intestinal resection on intestinal bile acid transport and hepatic bile acid and cholesterol biosynthesis in the context of the circulating bile acid pool. The results of massive intestinal resection on bile and cholesterol homeostasis could be predicted from the observed changes in ASBT expression. There was a graded increase in the size of the 
circulating bile acid pool as the amount of intestinal bile acid transport capacity increased. Bile acid biosynthetic enzyme activity was induced in an effort to replace the diminished bile acid pool. Cholesterol biosynthesis, as measured by HMGCoA reductase, was similarly induced as the bile acid pool size was reduced. The magnitude of the response for HMG-CoA reductase may have been greater because of wasting of both cholesterol and bile acids.

In summary, alterations in bile acid and cholesterol homeostasis are dependent on the type and location of the intestinal resection. Limited intestinal resection leads to hyperplasia and a commensurate nonspecific increase in ileal protein expression. Supraphysiologic expression of the ileal bile acid transporter results in a reduction in the bile acid pool size, which is associated with a paradoxical reduction in the bile acid and cholesterol biosynthetic enzyme activities. In contrast, massive intestinal resection is associated with a specific downregulation of ASBT protein expression. Bile acid pool size correlated with the amount of residual ASBT-expressing terminal ileum. Cholesterol and bile acid biosynthetic enzyme activities were inversely related to bile acid pool size.

\section{REFERENCES}

1. Shneider B 2001 Intestinal bile acid transport: biology, physiology and pathophysiology. J Pediatr Gastroenterol Nutr 32:407-417

2. Coppola CP, Gosche JR, Arrese M, Ancowitz B, Madsen J, Vanderhoof J, Shneider BL 1998 Molecular analysis of the adaptive response of intestinal bile acid transport after ileal resection. Gastroenterology 115:1172-1178

3. Thompson J, Langnas A, Pinch L, Kaufman S, Quigley E, Vanderhoof J 1995 Surgical approach to short-bowel syndrome: experience in a population of 160 patients. Ann Surg 222:600-605

4. Vanderhoof J 1996 Short bowel syndrome in children and small intestinal transplantation. Pediatr Clin North Am 43:533-550

5. Shneider BL, Thevananther S, Moyer MS, Walters HC, Rinaldo P, Devarajan P, Sun AQ, Dawson PA, Ananthanarayanan M 1997 Cloning and characterization of a novel peptidase from rat and human ileum. J Biol Chem 272:31006-31015

6. Bull LN, van Eijk MJT, Pawlikowska L, DeYoung JA, Juiun J, Liao M, Klomp LWJ, Lomri N, Berger R, Scharschmidt BF, Knisely AS, Houwen RHJ, Freimer NB 1998 Identification of a P-type ATPase mutated in two forms of hereditary cholestasis. Nat Genet 18:219-224

7. Arrese M, Trauner M, Sacchiero RJ, Crossman MW, Shneider BL 1998 Neither intestinal sequestration of bile acids nor common bile duct ligation modulate the expression and function of the rat ileal bile acid transporter. Hepatology 28:10811087

8. Shneider BL, Dawson PA, Christie DM, Hardikar W, Wong MH, Suchy FJ 1995 Cloning and molecular characterization of the ontogeny of a rat ileal sodiumdependent bile acid transporter. J Clin Invest 95:745-754
9. Crossman MW, Hauft SH, Gordon JI 1994 The mouse ileal lipid-binding protein gene: a model for studying axial patterning during gut morphogenesis. J Cell Biol 126:1547-1564

10. Ujhazy P, Ortiz D, Misra S, Li S, Moseley J, Jones H, Arias I 2001 Familial intrahepatic cholestasis 1: studies of localization and function. Hepatology 34:768775

11. Xu G, Shneider B, Shefer S, Nguyen L, Batta A, Tint G, Arrese M, Thevananther S, Ma L, Stengelin S, Kramer W, Greenblatt D, Pcolinsky M, Salen G 2000 Ileal bile acid transport regulates bile acid pool, synthesis and plasma cholesterol levels differently in cholesterol-fed rats and rabbits. J Lipid Res 41:298-304

12. Shefer S, Salen G, Batta A 1986 Methods of assay. In: Fears R, Sabine J, eds. Cholesterol $7 \alpha$-Hydroxylase ( $7 \alpha$-Monooxygenase). CRC Press, Boca Raton, FL, pp 43-49

13. Lowry O, Rosebrough N, Farr A, Randall R 1951 Protein measurement with the Folin phenol reagent. J Biol Chem 193:265-275

14. Xu G, Salen G, Shefer S, Tint G, Nguyen L, Chen T, Greenblatt D 1999 Increasing dietary cholesterol induces different regulation of classical and alternative bile acid synthesis. J Clin Invest 103:89-95

15. Shefer S, Kren B, Salen G, Steer C, Nguyen L, Chen T, Tint G, Batta A 1995 Regulation of bile acid synthesis by deoxycholic acid in the rat: different effects on cholesterol $7 \alpha$-hydroxylase and sterol 27-hydroxylase. Hepatology 22:1215-1221

16. Mok H, Perry P, Dowling R 1974 The control of bile acid pool size: effect of jejunal resection and phenobarbitone on bile acid metabolism in the rat. Gut 15:247-253

17. Hardison W, Rosenberg I 1977 Bile-salt deficiency in the steatorrhea following resection of the ileum and proximal colon. N Engl J Med 277:337-342

18. Poley J, Hofmann A 1976 Role of fat maldigestion in pathogenesis of steatorrhea in ileal resection. Gastroenterology 71:38-44

19. Hofmann A 1999 The continuing importance of bile acids in liver and intestinal diseases. Arch Intern Med 159:2647-2658

20. Heydorn S, Jeppesen P, Mortensen P 1999 Bile acid replacement therapy with cholylsarcosine for short-bowel syndrome. Scand J Gastroenterol 34:818-823

21. Gruy-Kapral C, Little K, Fordtran J, Meziere T, Hagey L, Hofmann A 1999 Conjugated bile acid replacement therapy for short-bowel syndrome. Gastroenterology 116:15-21

22. Rubin D, Levin M 1999 Intestinal adaptation: molecular analyses of a complex process. Gastroenterology 115:1291-1294

23. Hines OJ, Bilchik AJ, Zinner MJ, Skotzko MJ, Moser AJ, McFadden DW, Ashley SW 1994 Adaptation of the $\mathrm{Na}^{+}$/glucose cotransporter following intestinal resection. J Surg Res 57:22-27

24. Hines OJ, Bilchik AJ, McFadden DW, Skotzko MJ, Whang EE, Zinner MJ, Ashley SW 1994 Up-regulation of $\mathrm{Na}^{+}, \mathrm{K}^{+}$adenosine triphosphatase after massive intestinal resection. Surgery 116:401-408

25. Sonoyama K, Aoyama Y 1997 Different responses of apolipoprotein A-I, A-IV and $\mathrm{B}$ gene expression during intestinal adaptation to a massive small bowel resection in rats. Biosci Biotechnol Biochem 61:1810-1813

26. Sigalet D, Martir G 1998 Mechanisms underlying intestinal adaptation after massive intestinal resection in the rat. J Pediatr Surg 33:889-892

27. Dunphy J, Justice F, Taylor R, Fuller P 1999 mRNA levels of dipeptidyl peptidase IV decrease during intestinal adaptation. J Surg Res 87:130-133

28. Lu T, Makishima M, Repa J, Schoonjans K, Kerr T, Auwerx J, Mangelsdorf D 2000 Molecular basis for feedback regulation of bile acid synthesis by nuclear receptors. Mol Cell 6:507-515

29. Parks D, Blanchard S, Bledsoe R, Chandra G, Consler T, Kliewer S, Stimmel J, Wilson T, Zavacki A, Moore D, Lehmann J 1999 Bile acids: natural ligands for an orphan nuclear receptor. Science 284:1365-1368

30. Makishima M, Okamoto A, Repa J, Tu H, Learned R, Luk A, Hull M, Lustig K, Mangelsdorf D, Shan B 1999 Identification of a nuclear receptor for bile acids. Science 284:1362-1365

31. Chawla A, Saez E, Evans R 2000 Don’t know much bile-ology. Cell 103:1-4 